\title{
Blended Learning Approach to Second Language Learning in Elementary School
}

\author{
Olifia Rombot ${ }^{1}$, Endry Boeriswati ${ }^{2}$ and M. Atwi Suparman ${ }^{3}$ \\ 1, 2, 3 Universitas Negeri Jakarta, Indonesia, \\ 1olifiarombot_pd15s3@mahasiswa.unj.ac.id, ${ }^{1}$ olifia.rombot@binus.ac.id, \\ ${ }^{2}$ endry.boeriswati@unj.ac.id, ${ }^{3}$ suparmanatwi@gmail.com
}

\begin{abstract}
One difficulty in learning the second language is in understanding the contents of the reading text. This This study aims to improve reading comprehension skills with blended learning. This research is research and development in elementary schools. The population consists of fifth grade students in international schools. BIPA Learners (Indonesian for Foreign Speakers) are foreign nationals who live in Indonesia and learn Indonesian. BIPA students have difficulty understanding reading texts and interpreting words. This study concludes that learning with blended learning increased scores posttest with average value above the KKM and gave learners the opportunity and more time to repeatedly read reading texts. Students can learn the material first before learning in class so that they gain knowledge or reading comprehension skills in accordance with their respective abilities.
\end{abstract}

Keywords: Blended Learning, Elementary School, Reading Comprehension

\section{PENDAHULUAN}

Memahami isi bacaan dengan baik tidak mudah bagi siswa sekolah dasar pada umumnya. Jurnal Bahasa, Sastra dan Pembelajaran menunjukkan bukti hasil penelitian bahwa permasalahan yang sering muncul dalam pembelajaran membaca pemahaman, yaitu: 1) kurangnya minat, motivasi dan keseriusan siswa terhadap pembelajaran membaca; 2) bahan bacaan yang digunakan guru kurang menarik sehingga tidak menumbuhkan minat siswa dalam pembelajaran membaca; 3) model pembelajaran yang digunakan guru kurang efektif, kurang memancing minat siswa dan tidak memotivasi siswa secara maksimal [1]. Penelitian ini dilakukan pada siswa dengan bahasa Indonesia sebagai bahasa pertamanya.

Permasalahan dalam memahami bacaan juga dialami peserta didik yang mempelajari bahasa kedua. Pemelajar asing yang mempelajari bahasa Indonesia disingkat BIPA (Bahasa Indonesia Bagi Penutur Asing) mengalami masalah yang sama dalam memahami bacaan karena pembelajaran bahasa kedua bukan suatu hal (proses) yang sederhana. Bahasa kedua akan rumit dipelajari jika pembelajar tidak memiliki faktor pendukung yang memadai. Abdul Chaer menyebutkan lima faktor penentu dalam pembelajaran bahasa kedua, yaitu: a) faktor motivasi; b) faktor usia; c) faktor penyajian formal; d) faktor bahasa pertama; e) faktor lingkungan [2].

Di sisi lain kurangnya pengenalan kata dan arti kata juga menjadi permasalahan dalam membaca pemahaman. Jurnal Pendidikan Dasar di Turkey menemukan hasil penelitian bahwa pemahaman bacaan berkaitan erat dengan pengenalan kata, arti kata, analisis fonetik dan strukturnya. Ketika keterampilan pengenalan kata tidak dikembangkan, masalah muncul dalam 
pemahaman bacaan [3]. Masalah ini juga ditemukan pada pembelajaran membaca pemahaman siswa BIPA di sekolah internasional di Simprug, Jakarta. Kurangnya pengenalan kata dan arti kata pada teks bacaan menyulitkan dalam memahami teks bacaan.

Berdasarkan hasil observasi pada pembelajaran membaca pemahaman bahasa Indonesia di kelas ILA (Indonesian Language Acquisition) di Sekolah ABC di daerah Simprug didapati hasil bahwa kesulitan siswa memahami bacaan karena minimnya kosa kota dan sulitnya memahami arti kata yang ditemukan dalam bacaan. Guru kehabisan waktu hanya untuk menjelaskan arti kata karena $98 \%$ siswa maju dan atau angkat tangan untuk bertanya tentang arti kata yang ditemukan dalam bacaan. Kholid A. Harras mendefinisikan bahasa kedua adalah bahasa yang diperoleh anak setelah mereka memperoleh bahasa pertama [2]. Bahasa kedua diperoleh dan dipelajari dengan sadar, sedangkan pemerolehan bahasa pertama diperoleh sang anak tanpa sadar dari kesehariannya bersama keluarganya. Pemerolehan keduanya lebih kepada proses pemahaman bahasa belajar secara sadar.

Pada dasarnya proses perolehan bahasa pertama (B1) dan B2 tidak memiliki perbedaan subtansi dan keduanya harus memiliki tiga kompetensi, yaitu: Kompetensi Semantik, Kompetensi Sintaksis, dan Kompetensi Fonologi. Ketiga kompetensi tersebut merupakan subtansi dari kompetensi linguistik [4]. Anak-anak yang mempelajari bahasa kedua pada usia 6 tahun mendapatkan keuntungan dalam aspek fonologi yaitu bahwa anak-anak dapat mengucapkan kata-kata bahasa kedua hampir sama dengan penutur asli. Akan tetapi kesalahankesalahan gramatikal masih terjadi ketika mereka merangkaikan kalimat-kalimat yang lebih kompleks strukturnya. Sementara orang dewasa cenderung diuntungkan dalam aspek morfologi dan sintaksis [5].

Hasil wawacara dengan PYP Koordinator Bahasa Indonesia dan BIPA di Sekolah ABC di daerah Simprug memaparkan bahwa tidak mudah bagi siswa asing belajar bahasa Indonesia. Siswa BIPA merupakan WNA dengan negara asal Korea, Tiongkok, Jepang, India, Pakistan, Australia, Serbia, Amerika dan Perancis. WNA asal India dan Korea paling banyak dibanding negara lainnya. Siswa asing tersebut mempelajari dua atau tiga bahasa karena lingkungannya. Bahasa Indonesia merupakan bahasa kedua yang mereka pelajari. Guru menjelaskan bahwa siswa asing menggunakan bahasa Indonesia lebih sering hanya kepada pekerja di rumahnya seperti asisten rumah tangga, penjaga keamanan dan supir pribadinya. Perbedaan budaya dan lingkungan sangat mempengaruhi motivasi anak mempelajari Bahasa Indonesia.

Faktor motivasi juga sangat penting dalam mempengaruhi pembelajaran bahasa kedua. Hal ini ditegaskan Ellis dalam tulisan ilmiahnya bahwa pembelajaran bahasa Indonesia bagi penutur asing memiliki karakteristik berbeda dengan pembelajaran bahasa Indonesia bagi penutur asli. Salah satu hal yang memengaruhi karakteristik pembelajaran BIPA adalah motivasi siswa dalam mempelajari bahasa Indonesia. Motivasi belajar muncul dalam suasana belajar yang menyenangkan sehingga guru dituntut untuk kreatif dalam merancang kegiatan pembelajaran yang dapat menumbuhkan motivasi siswa agar terlibat secara penuh, sehingga tujuan pembelajaran dapat tercapai dengan maksimal [6]. Selain itu proses pembelajaran harus sesuai dengan tugas sehari-hari dan lingkungan siswa agar dapat mencapai hasil yang optimal. Dengan demikian siswa dapat lebih bersemangat mengikuti pelajaran.

Hasil observasi pada studi pendahuluan menunjukkan masih rendahnya motivasi belajar siswa BIPA di kelas V. Para siswa sering merasa bosan karena terlalu banyak mendengarkan guru berbicara, membaca teks yang didominasi oleh teks, hingga bosan mengerjakan latihanlatihan. Pada titik jenuh itu siswa lebih mudah kehilangan motivasi belajar. Pada kondisi ini siswa memilih untuk melakukan kegiatan yang lebih mereka sukai seperti mencoret-coret buku catatan, ngobrol dengan teman atau keluar meninggalkan kelas dengan alasan ke toilet atau 
sekedar mengambil air minum. Kesulitan dalam memahami penjelasan guru berbahasa Indonesia dan minimnya kosa kata sangat menyulitkan murid dan guru dalam berkomunikasi.

Berdasarkan paparan di atas maka untuk menciptakan pembelajaran yang menyenangkan dan menumbuhkan motivasi belajar bahasa kedua khususnya pada pembelajaran membaca pemahaman maka perlu adanya pendekatan pembelajaran dengan blended learning untuk siswa BIPA kelas V. Berdasarkan data penelitan terdahulu bahwa motivasi terintegratif dengan komunikasi pada anak dalam lingkungan belajar yang menyenangkan akan mempermudah proses pemerolehan bahasa kedua pada anak. Pivec dan Dziabenko dalam Talak-Kiryk menambahkan bahwa suatu proses pembelajaran bahasa harus menarik, mudah dan harus menyenangkan untuk dipelajari [7].

Hasil penelitan menunjukkan bahwa penggunaan teknologi pada pembelajaran di Sekolah Dasar dapat meningkatkan kemampuan siswa untuk menerima informasi, mengintrepretasikan dan mengkomunikasikan ide dengan cara yang kreatif serta mampu meningkatkan motivasi belajar untuk menemukan jawaban. Melalui penggunaan teknologi dapat menumbuhkan keinginan guru mempelajari teknologi dan mau meningkatkan kapasitasnya baik dalam menyiapkan sumber belajar maupun pengoperasikan teknologi [8]. Pengunaan blended learning dalam pembelajaran berarti adanya akses dan transfer informasi melalui metode interaksi yang menggabungkan sesi tatap muka konvensional dengan pembelajaran secara online atau daring (dalam jaringan) [9].

Penelitian pada pembelajaran bahasa menggunakan blended learning menunjukkan hasil bahwa dengan menggabungkan pembelajaran tatap muka dengan teknologi dapat menciptakan lingkungan belajar mengajar yang efektif bagi siswa dan guru. Siswa yang belajar dengan menggunakan blended learning memiliki upaya yang lebih tinggi dan hasil test yang lebih baik pada nilai bahasa dibanding dengan siswa yang menggunakan buku teks. Siswa juga memiliki lebih banyak tanggung jawab dan meningkatkan partisipasi pada pembelajan Bahasa kedua [8].

Dalam berbagai sumber, blended learning /b-learning atau mixed/hybrid disebut sebagai percampuran atau penggabungan. Penggabungan atau hibrida [9]. Pengunaan blended learning dalam pembelajaran berarti adanya akses dan transfer informasi melalui metode interaksi yang menggabungkan sesi tatap muka konvensional dengan pembelajaran secara online atau daring (dalam jaringan) [10].

Blended learning adalah konsep yang mencakup proses belajar mengajar yang menggabungkan pengajaran tatap muka dan pengajaran yang didukung oleh TIK. Blended learning menggabungkan instruksi langsung, instruksi tidak langsung, pengajaran kolaboratif, pembelajaran dengan bantuan komputer/Gadget individual [11]. Karena sifatnya yang menggabungkan (Blend) maka siswa tidak kehilangan kesempatan berinteraksi dalam diskusi dengan guru dan siswa lainnya dan menyenangkan karena sesuai dengan karakteristik generasi digital. Pembelajaran melalui konsep model blended learning jika direcanakan dengan baik dapat menumbuhkan motivasi belajar, disiplin dan tanggung jawab para siswa.

Penelitian untuk pengembangan model pembelajaran bahasa Indonesia bagi penutur asing dalam pemahaman membaca perlu dilaksanakan karena model pembelajaran yang ada belum memenuhi unsur efektif, efisien dan engaging bagi para siswa. Oleh karena itu perlu dilaksanakan penelitian dengan pendekatan blended learning untuk siswa BIPA kelas V SD dengan harapan siswa dapat memiliki waktu lebih banyak dalam memahami isi bacaan baik secara tatap muka maupun dalam jaringan.

\section{METODE PENELITIAN}


Penelitian ini menggunakan pendekatan penelitian dan pengembangan (research and development), dengan alasan karena sesuai dengan tujuan yang hendak dicapai. Sedangkan model penelitian pengembangan yang dipilih adalah model penelitian dan pengembangan pendidikan yang dikembangkan oleh Borg dan Gall (2007: 772). Menurut Borg dan Gall, "educational research and development $(R \& D)$ is a process used to develop and validate educational production" [12]. Dengan pengertian tersebut maka rangkaian langkah-langkah penelitian dan pengembangan dilakukan secara siklis, dan pada setiap langkah yang akan dilalui atau dilakukan selalu mengacu pada hasil langkah sebelumnya hingga pada akhirnya diperoleh suatu produk pendidikan yang baru.

Alasan lain penggunaan pendekatan penelitian dan pengembangan karena dipandang tepat untuk mengembangkan model pembelajaran yang tujuannya tidak sekedar menemukan profil implementasi atau praktik-praktik pembelajaran, namun lebih dari itu, yaitu mengembangkan model pembelajaran yang efektif dan mudah dalam penerapannya, sesuai kondisi dan kebutuhan nyata di sekolah. Penelitian dan pengembangan juga memiliki keunggulan, terutama jika dilihat dari prosedur kerjanya yang sangat memperhatikan kebutuhan dan situasi nyata di sekolah dan bersifat sistematik [13].

Pendekatan penelitian dan pengembangan pendidikan pada penelitian ini dimanfaatkan untuk menghasilkan model pembelajaran pemahaman membaca siswa BIPA kelas V SD yang efektif, efisien dan engaging sehingga mempelajari bahasa Indonesia merupakan hal yang menyenangkan dan meningkatnya keterampilan pemahaman bacaan dalam pembelajaran BIPA di SD.

Borg \& Gall menjelaskan serangkaian tahap atau langkah yang harus ditempuh dalam pendekatan ini yaitu; (1) Research and information collecting; (2) planning; (3) develop preliminary form of product; (4) preliminary field testing; (5) main product revision; (6) main field testing; (7) operational product revision; (8) operational field testing; (9) final product revision; dan (10) dissemination and implementation. Hasil penelitian yang dituangkan dalam tulisan ini merupakan sebagaian dari tahapan-tahapan yang ada yaitu tahap dari studi pendahuluan sampai test uji coba pada kelompok kecil (small group evaluation) saja.

\section{HASIL DAN PEMBAHASAN}

Penelitiaan ini dilakukan pada bulan Maret 2019 di SD ABC di terletak di daerah Simprug, Jakarta dengan jumlah responden lima orang WNA. Terdiri dari tiga perempuan dan dua laki-laki berusia 9 atau 10 tahun. Mereka berasal dari Korea Selatan, Jepang, India, Amerika, Tiongkok. Pelaksanan penelitian dilakukan selama enam kali dengan rincian: tiga kali pertemuan tatap muka dan tiga kali pertemuan daring.

Pada awal pertemuan daring siswa diberikan akses melalui laman padlet guru untuk dapat mengakses teks bacaan dan video pendukung pembelajaran. Guru mengirimkan link yang dapat diakses oleh murid melalui orang tua. Guru menjelaskan langkah-langkah yang harus dipelajari siswa, antara lain: 1) siswa dibantu orang tuanya membuka laman padlet.com/olifia_rombot/*** untuk dapat mengisi soal pretes, 2) siswa mencoba mengerjakan pretest secara mandiri, 3) siswa diperkenankan membaca teks bacaan berupa komik digital subtema 1, dan 3) siswa dapat menuliskan arti kata baru yang ditemui.

Pada pertemua tatap muka pertama di dalam kelas, guru meminta kepada siswa untuk membaca dialog komik digital dalam kelompok. Siswa secara bergantian membaca sesuai dengan peranan dalam teks bacaannya. Guru memutarkan video pendukung dan kemudian menanyakan kosa kata baru apa yang ditemukan, siswa dapat menuliskan langsung dilaman padlet dalam pembelajaran di kelas. Diakhir pembelajaran guru memberikan postest kepada 
para murid. Hasil pretest dan posttest dibandingkan untuk subtema 1. Hasilnya menunjukkan ada peningkatan nilai posttest dan penambahan kata dalam kalimat yang lebih panjang untuk pertanyaan essay.

Kemudian pada pertemuan daring yang kedua siswa diberikan akses untuk mempelajari materi pada subtema 2 dengan judul "Naik Delman". Siswa melakukan proses yang sama mulai dari menjawab soal pretest, membaca komik digital dan menyimak video. Siswa dapat menuliskan arti kata baru yang ditemukan. Guru dapat melihat hasil pretest secara langsung.

Selanjutnya, pada pertemuan tatap muka kedua, guru meminta 4 orang membaca sesuai dengan dialog dan peran dalam komik berjudul "Naik Delman". Siswa bernyanyi bersama lagu "Naik Delman" dan diminta menuliskan pengalaman naik delman. Siswa mengerjakan soal postest diakhir pembelajaran. Hasilnya ada peningkatan kalimat yang ditulis dan semangat belajar nampak dari keaktifan siswa membaca dan menceritakan kembali bacaan dengan bahasanya sendiri.

Pada pertemuan daring yang ketiga, siswa diberikan akses yang sama untuk mempelajari materi dengan subtema "Candi Borobudur". Teks bacaan komik lebih banyak dan materi video juga lebih banyak. Siswa mengerjakan soal pretest secara daring dari rumah mereka masingmasing.

Pertemuan tatap muka ketiga, guru meminta siswa bercerita tentang "Candi Borobudur". Ada dua siswa dari lima yang masih kesulitan memahami arti kata baru tetapi dapat mulai menyukai mencari di kamus KBBI online dengan senang hati. Diakhir pertemuan siswa juga mengerjakan postets. Siswa juga belajar membuat komiknya sendiri baik di kelas tetapi karena keterbatasan waktu maka komik dibawa pulang untuk dikerjakan bersama orang tua.

Hasil penelitian dari uji t-test (one-sample test) didapati nilai 0,000 maka terdapat cukup bukti untuk menyatakan bahwa rata-rata nilai posttest pada pembelajaran BIPA dengan blended learning lebih dari nilai KKM $(>65)$. Pembelajaran dengan blended learning memberi waktu dan ruang yang lebih besar untuk peserta didik belajar dan mempersiapkan diri. Siswa dapat lebih memahami teks bacaan karena dapat membacanya berulang kali dan menemukan cara belajarnya sendiri sesuai dengan kemampuannya masing-masing.

\section{SIMPULAN}

Pembelajaran bahasa kedua memiliki tantangannya tersendiri bagi guru dan juga siswa. Pembelajaran dengan blended learning memberikan kesempatan dan waktu yang lebih banyak baik secara daring maupun waktu untuk berinteraksi dalam pembelajaran tatap muka di kelas bagi siswa asing yang belajar bahasa Indonesia dan meningkatkan hasil belajar siswa. Pada pembelajaran pemahaman bacaan, peserta didik dapat membaca berulang kali teks bacaan, memaknai kata dan memahami kalimat yang dibacanya. Guru dituntut untuk memiliki kemapuan menyusun digital konten dalam bentuk bacaan digital, video pembelajaran serta dapat memberikan sumber bahan digital lainnya yang dapat diakses secara baik. Media pembelajaran digital yang manarik seperti komik digital sangat dibutuhkan untuk menumbuhkan kesukaan siswa BIPA belajar bahasa Indonesia. Orang tua dari siswa pemelajar BIPA melalui blended learning juga memiliki kesempatan untuk belajar bahasa Indonesia bersama anaknya di rumah. 


\section{REFERENCES}

[1] Fuzidri, "Peningkatan Keterampilan Pemahaman Membaca Melalui Metode Pembelajaran Kooperatif Tipe CIRC," J. Bahasa, Sastra dan Pembelajaran, vol. 2, no. 3, pp. 109-110, 2014.

[2] A. Chaer, Psikolingustik: Kajian Teoritik. Jakarta: Rineka Cipta, 2009.

[3] H. Kodan, "Determination of Reading Levels of Primary School Students," Univers. J. Educ. Res., vol. 5, no. 11, pp. 1962-1969, 2017.

[4] S. Endorat, "Makalah Pendidikan Bahasa "Faktor Usia dalam Pemerolehan Bahasa Kedua"," 2014. [Online]. Available: https://amortallearner.net/2014/11/26/faktor-usiadalam-pemerolehan-bahasa-kedua/. [Accessed: 29-Mar-2018].

[5] I. Suyitno, "Pengembangan Bahan Ajar Bahasa Indonesia untuk Penutur Asing (BIPA) berdasarkan Hasil Analisis Kebutuhan Belajar,” Wacana, J. Humanit. Indones., vol. 9, no. 1, p. 62, 2007.

[6] E. R. Artyana, Ragam Permainan dalam Pembelajaran Berbicara BIPA. 2014.

[7] B. Klimova and J. Kacet, "Efficacy of computer games on language learning," Turkish Online J. Educ. Technol., vol. 16, no. 4, pp. 19-26, 2017.

[8] S. Danče, "The influence of using the information and communications technology in primary education," Procedia - Soc. Behav. Sci., vol. 2, no. 2, pp. 4270-4273, 2010.

[9] M. Driscoll, "IBM Global Services Consultants point of view."

[10] T. Yigit, A. Koyun, A. S. Yuksel, and I. A. Cankaya, "Evaluation of Blended Learning Approach in Computer Engineering Education," Procedia - Soc. Behav. Sci., vol. 141, pp. 807-812, 2014.

[11] D. Lalima and K. Lata Dangwal, "Blended Learning: An Innovative Approach," Univers. J. Educ. Res., vol. 5, no. 1, pp. 129-136, 2017.

[12] M. D. Gall, J. P. Gall, and W. R. Borg, Education Researh, 8th ed. United States of America: Pearson, 2007.

[13] K. Saddhono, A. Hasibuan, and M. I. Bakhtiar, "Facebook as A Learning Media in TISOL (Teaching Indonesian to Speakers of Other Languages) Learning to Support The Independency of Foreign Students in Indonesia," in Journal of Physics: Conference Series, 2019, vol. 1254, no. 1, p. 12061. 